\title{
Attenuated Renal and Hepatic Cells Apoptosis Following Swimming Exercise Supplemented with Garlic Extract in Old Rats
}

This article was published in the following Dove Press journal: Clinical Interventions in Aging

\author{
Parvin Farzanegi' \\ Hajar Abbaszadeh' \\ Farzaneh Farokhi ${ }^{2}$ \\ Saleh Rahmati- \\ Ahmadabad $\left(\mathbb{D}^{3}\right.$ \\ Seyed Ali Hosseini ${ }^{4}$ \\ Abdi Ahmad (D) ${ }^{5}$ \\ Mohammad Reza Mazandarani ${ }^{6}$ \\ Iraj Rezaei' \\ Mohammad Shokrie' \\ Exir Vizvari ${ }^{7}$ \\ Hadi Alinejad' \\ Mohammad Ali Azarbayjani iD ${ }^{8}$ \\ 'Department of Exercise Physiology, Sari \\ Branch, Islamic Azad University, Sari, Iran; \\ ${ }^{2}$ Department of Biology, Faculty of Basic \\ Sciences, Sari Branch, Islamic Azad \\ University, Sari, Iran; ${ }^{3}$ Department of \\ Physical Education, Pardis Branch, Islamic \\ Azad University, Pardis, Iran; \\ ${ }^{4}$ Department of Sport Physiology, \\ Marvdasht Branch, Islamic Azad \\ University, Marvdasht, Iran; ${ }^{5}$ Department \\ of Physical Education, Faculty of Physical \\ Education, Ayatollah Amoli Branch, \\ Islamic Azad University, Amol, Iran; \\ ${ }^{6}$ Department of Physical Education, \\ Farhangian University, Gorgan, Iran; \\ ${ }^{7}$ Department of Exercise Physiology, \\ Faculty of Humanities, Shams Institute of \\ Higher Education, Gonbad Kavous, Iran; \\ ${ }^{8}$ Department of Exercise Physiology, \\ Islamic Azad University, Central Tehran \\ Branch, Tehran, Iran
}

Correspondence: Parvin Farzaneg Department of Exercise Physiology, Sari Branch, Islamic Azad University, Sari, Iran Email parvin.farzanegi@gmail.com
Background/Objective: One of the problems associated with aging is the development of apoptosis in different tissues. There is evidence that physical activity and herbal remedies can be useful. This study aimed to determine the effect of swimming training (SW) alone or combined with garlic extract on renal and hepatic cells apoptosis, as wellas on the liver and kidney function biomarkers in old rats.

Methods: A total of 35 old rats (aged 40-50 weeks) were randomly divided into 5 groups including control, saline (S), exercise training (ET), garlic $(\mathrm{G})$ and exercise training+ garlic (ET. $\mathrm{G})$ groups. Exercise was started for $5 \mathrm{~min} /$ day and then gradually extended to $60 \mathrm{~min} /$ day and the $\mathrm{G}$ and $\mathrm{E}+\mathrm{G}$ groups received $1 \mathrm{~mL} / \mathrm{kg}$ of this mixture by gavage. Twenty-four hours after completion of 8 weeks training, liver, kidney and blood samples were collected for histopathological examinations, liver and kidney functions, oxidative stress and apoptosis biomarkers.

Results: The tissue sections of the SW exercise, control and saline groups showed some mild histopathological changes in liver and kidney, while SW supplemented with garlic prevented these damages. The SW alone or supplemented with garlic significantly increased the Bcl-2 value and declined the BAX level in both liver and kidney $(\mathrm{p}<0.05)$. The activities of catalase (CAT) and superoxide dismutase (SOD) in the liver and kidney of the control and saline groups were lower than those in $\mathrm{E}, \mathrm{G}$ and $\mathrm{G}+\mathrm{E}$ groups, while a significant increase for malondialdehyde (MDA) value was found in the control and saline groups. Furthermore, the $\mathrm{E}+\mathrm{G}$ significantly declined the activity of hepatic (ALT, AST and ALP) and renal damage (uric acid, urea and creatinine) biomarkers compared to the control and saline groups $(\mathrm{p}<0.05)$.

Discussion: Swimming exercise supplemented with garlic extract not only improves antioxidant capacity but also declines oxidative damages and apoptosis through reducing Bax levels and enhancing Bcl-2 value.

Keywords: apoptosis, garlic extract, antioxidant, oxidative stress, swimming exercise, old rats

\section{Introduction}

Apoptosis or programmed cell death is a process that occurs normally during different physiological and pathological conditions and plays as a homeostatic or defense mechanism that maintains cell populations in tissues. ${ }^{1}$ Although there are a lot of stimuli and conditions, including aging, irradiation, drugs, DNA damage, hypoxia, and cellular damages that can trigger apoptosis, this process is usually regulated by anti-apoptotic Bcl-2 protein and pro-apoptotic protein Bax. ${ }^{2}$ Recent studies have shown that overexpression of Bcl-2 promotes cell survival, while up-regulation of Bax is associated with cell death through activation and releasing of Caspases. ${ }^{3}$ 
Recent investigations have demonstrated that regular exercise, such as swimming and aerobic training, is one of the important factors for the protection of different tissues against a variety of acute and chronic diseases. ${ }^{4}$ Recent evidence have also indicated that exercises, especially endurance training, swimming and aerobic exercises, can exhibit resistance against the aging, lipid peroxidation, inflammation and apoptosis induced by different chemical agents. ${ }^{4}$ Furthermore, there is clear evidence that regular exercise trainings can inhibit free radicals production and mediate decreased reactive oxygen species (ROS), inflammation, ischemia and oxidative stress. ${ }^{5}$ Recently, dietary plants, identified from herbal medicine are providing an opportunity for the appearance of new types of therapeutics. Among them, garlic (Allium sativum) has been utilized in herbal medicine for its unique antioxidant and anti-inflammatory properties. ${ }^{6,7}$

Nevertheless, there are conflicting data on the effect of exercises on apoptosis in old subjects. Regulation of apoptosis after exercise still remains controversial since some studies demonstrated both an overexpression and an underexpression of cell death. ${ }^{8}$ For example, some studies proposed that exercise enhances apoptosis and that serves to remove certain damaged cells without a pronounced inflammatory response or oxidative stress, thus ensuring optimal tissue function. ${ }^{8-10}$ On the other hand, some studies indicated the anti-apoptotic effect of exercises in several tissues, especially liver and kidney. ${ }^{11,12}$

Although several studies have considered the effects of different exercises on liver and kidney functions, less information is available about renal and hepatic cell apoptosis after swimming training exercise in old subjects. We hypothesize swimming exercise may help maintain liver and renal health by excreting toxic metabolites, decreasing oxidative stress and apoptotic factors in old subjects. Therefore, the present study was designed to investigate the effects of SW exercise alone or supplemented with garlic extract on histological alterations, liver and kidney functions, as well as antioxidant activities, oxidative stress, and apoptosis biomarkers in old rats.

\section{Materials and Methods}

\section{Animals}

In this experimental study, 35 male old Wistar rats ${ }^{13} 40-50$ weeks of age with a body weight of 250-300 g were selected at laboratory animal research center of the Islamic Azad University of Sari. After a period of 2 weeks adaptation with laboratory environment, rats were randomly allocated into 5 groups including control, saline (S), exercise training (ET), garlic (G) and Exercise training + garlic (ET.G) groups. Rats in each group were housed 3 per cage $(30 \times 15 \times 15 \mathrm{~cm})$ in a climate-controlled room (ambient temperature of $22 \pm 2^{\circ} \mathrm{C}$, humidity $55 \pm 5$, and a 12:12 light/dark cycle) with adequate standard laboratory food and tap water. The study was approved by the animal care and use committee at the Islamic Azad University of Sari (1396/3). The American College of Laboratory Animal Medicine's (ACLAM) "Guidelines for Adequate Veterinary Care" (ACLAM 1996) ACLAM [American College of Laboratory Animal Medicine] Adequate Veterinary Care. 1996. [accessed May 10, 2010]. Available at www.aclam.org/education/guidelines/posi tion adequatecare.html. Were followed by the welfare of the laboratory animals".

\section{Study Groups}

Swimming Exercise Training

Before exercise training, Wistar rats were exercised $5 \mathrm{~min}$ for 5 days to be familiar with water. Swimming training was programmed in an experimental swimming pool (30-$32^{\circ} \mathrm{C}$, water depth: $44 \mathrm{~cm}$; radius $120 \mathrm{~cm}$ ), 3 days per week for a total period of 8 consecutive weeks. The swimming was started for $5 \mathrm{~min} /$ day and then gradually extended to $60 \mathrm{~min}$ per day (Table 1). ${ }^{14}$

\section{Garlic and Saline Treatments}

Fresh garlic was collected from a local market and skinned and sliced. Briefly, $50 \mathrm{~g}$ sliced garlic was crushed and mixed in a blender for 1 minute, then soaked in methanol in the ratio 1:3. It was naturally extracted for 3 months at room temperature, the mixture was separated in test tubes by centrifugation at $3000 \mathrm{rpm}$, the filtrate was dried in oven $37{ }^{\circ} \mathrm{C}$ for $24 \mathrm{~h}$. After the process of extraction, 1.4 $\mathrm{g}$ garlic powder was mixed with $56 \mathrm{~mL} \mathrm{dH}_{2} \mathrm{O}$. The $\mathrm{G}$ and $\mathrm{E}$ $+\mathrm{G}$ groups received $1 \mathrm{~mL} / \mathrm{kg}$ of this mixture by gavage for 8 weeks. Similarly, the $\mathrm{S}$ group received $1 \mathrm{~mL} / \mathrm{kg}$ of saline by gavage for 8 weeks. ${ }^{15}$

\section{Blood and Tissue Samples}

Rats were exposed to intraperitoneal ketamine $(30-50 \mathrm{mg} / \mathrm{kg}$ ) and xylazine $(3-5 \mathrm{mg} / \mathrm{kg}$ ) anesthesia and the liver and kidneys were isolated and stored at $-80{ }^{\circ} \mathrm{C}$ until further examination. A fragment of liver and kidney tissues was also separated for microscopic examination. Liver and kidney samples were homogenized in 
phosphate buffer (pH 7.0) at $4^{\circ} \mathrm{C}$ with homogenizer. For histological examinations, fragment of liver and kidney tissue was removed and fixed in $10 \%$ formalin for at least $48 \mathrm{~h}$. Fragments were dehydrated in graded series of ethanol, embedded in paraffin and sectioned using an automatic microtome at $5 \mathrm{~mm}$ thickness. For histological processing, the sectioned tissues were stained with haematoxylin-eosin (H\&E) and examined for morphological and histological parameters by light microscopy. Blood samples were immediately withdrawn from the abdominal aorta for the measurement of blood and serum parameters.

\section{$\mathrm{Bcl}-2$ and $\mathrm{BAX}$ Measurements}

Levels of Bcl-2 and BAX in the liver and kidney tissue samples were measured with the commercial ELISA kits provided from ZellBio Company (Germany). The results were expressed in $\mathrm{ng} / \mathrm{mg} /$ tissue.

\section{Liver-Specific Enzymes}

Concentrations of liver-specific enzymes including blood ALT (119600 R910), AST (118600R910) and ALP (102 600 R910) were evaluated with the commercial ELISA kits provided from Pars Azmun Company (Iran). The results were expressed in Unit/L.

\section{Urea, Uric Acid and Creatinine}

Levels of urea, uric acid and creatinine in the serum of all samples were measured by the rat urea (R910 400 129), rat uric acid (R910 300 131) and rat creatinine (R910 600109) kits provided by Pars Azmun Company (Iran).

\section{Lipid Peroxidation}

Lipid peroxidation in liver and kidney tissues was determined by measuring the concentration of malondialdehyde (MDA) using thiobarbituric acid reactive substances (TBARS), which was assessed with a specific kit provided from ZellBio company (MDA ELISA Kit=ZB-0156R9648, Germany). Results are presented in nmol/g/liver and kidney.

\section{Antioxidant Enzymes}

The activity of superoxide dismutase (SOD ELISA Kit=ZB-0168-R9648) and catalase (CAT ELISA Kit $=\mathrm{ZB}-0869-\mathrm{R} 9648$ ) enzymes in liver and kidney tissues was assessed using the commercial ELISA kits provided from ZellBio Company (Germany). The results were expressed in Unit/L.

\section{Statistical Analysis}

All data are presented as means \pm SD. The mean of all findings between the different groups was compared using the One-Way ANOVA: Post Hoc-Tukey's test. Data were analyzed using SPSS, version 19. A probability of less than 0.05 was considered as significant.

\section{Results}

\section{Histopathological Considerations}

The histopathological examination of liver tissue from different groups can be seen in Figure 1. Light microscopic observation revealed the liver tissue from control (Figure 1A), saline (Figure 1B) and SW exercise (Figure 1C) groups show increased blood in central vein along with inflammation and higher number of plasma cells in portal space; however, lobular and hepatocytes were normal in structure. The sections of liver from G (Figure 1D) and E.G (Figure 1E) groups showed milder abnormalities compared to the other groups.

The microscopic examinations of the kidney tissue for different groups are demonstrated in Figure 2. The kidney of the control (Figure 2A), saline (Figure 2B) and exercise (Figure 2C) showed mild necrosis and sloughing of epithelium, mild intratubular hemorrhage and renal tubular dilatation, tubular vacuolation and mild inflammation. The sections of the $\mathrm{G}$ (Figure 2D) and $\mathrm{E}+\mathrm{G}$ group (Figure 2E) did not show any significant pathological damages.

\section{Renal Apoptosis Biomarkers}

The mean of renal Bcl-2, BAX and BAX/Bcl-2 values in all groups is shown in Table 2. There was a significant difference in the mean levels of all parameters $(\mathrm{p}<0.001)$. The saline and control groups showed the lowest mean level of Bcl-2, which the differences were significant as compared to the exercise $(\mathrm{p}<0.001 ; \mathrm{p}=0.003)$, garlic $(\mathrm{p}=0.001 ; \mathrm{p}=0.001)$ and $\mathrm{EG}(\mathrm{p}<0.001 ; \mathrm{p}<0.001)$ groups.

Table I Swimming Exercise Training Protocol

\begin{tabular}{|l|l|l|l|}
\hline Week Day & I & $\mathbf{2}$ & $\mathbf{3}$ \\
\hline 1 & $5-6$ & $7-8$ & $9-10$ \\
2 & $11-13$ & $14-16$ & $17-19$ \\
3 & $20-21$ & $22-23$ & $24-25$ \\
4 & $26-28$ & $29-31$ & $32-34$ \\
5 & $35-36$ & $37-38$ & $39-40$ \\
6 & $4 I-43$ & $44-46$ & $47-49$ \\
7 & $50-51$ & $52-53$ & $54-55$ \\
8 & $56-57$ & $58-59$ & $59-60$ \\
\hline
\end{tabular}


The E.G group demonstrated the highest mean value of Bcl-2 compared to the other groups. The mean of BAX level in the control and saline groups was significantly higher than that in the exercise $(p=0.004$ and $p=0.005)$, garlic $(p=0.029$ and $p=0.04)$ and E.G $(p=0.001$ and $\mathrm{p}=0.002$ ) groups. The E.G group exhibited the lowest mean value of BAX compared to the other groups. The $\mathrm{BAX} / \mathrm{Bcl}-2$ ratio in the control and saline groups was significantly higher than that in the exercise $(p<0.001$ and $\mathrm{p}<0.001)$, garlic $(\mathrm{p}=0.002$ and $\mathrm{p}<0.001)$ and E.G $(p<0.001$ and $p<0.001)$ groups. The E.G group depicted the lowest mean value of $\mathrm{BAX} / \mathrm{Bcl}-2$ ratio compared to the other groups (Table 2).

\section{Liver Apoptosis Biomarkers}

Comparison of the mean of hepatic Bcl-2, BAX and BAX/ Bcl-2 values between all groups is demonstrated in Table 2. There was a significant difference in the mean values of all these parameters between groups $(p<0.001)$. The saline and control groups exhibited a significant lower mean Bcl2 concentration compared to the exercise $(\mathrm{p}<0.0001$; $\mathrm{p}<0.0001)$, garlic $(\mathrm{p}<0.0001 ; \mathrm{p}<0.0001)$ and $\mathrm{EG}$ $(\mathrm{p}<0.0001 ; \mathrm{p}<0.0001)$ groups. The E.G group demonstrated the highest mean value of Bcl-2 compared to the other groups. This difference was significant even in comparison with the exercise alone group $(\mathrm{p}=0.04)$.

The mean of BAX level in the control and saline groups was significantly greater than the exercise $(p=0.034$ and $p=0.016)$, garlic $(p=0.011$ and $p=0.005)$ and E.G $(p=0.004$ and $p=0.002$ ) groups. In contrast, the E.G group showed the lowest mean value of BAX compared to the other groups; however, we could not find a significant difference between the $\mathrm{E}, \mathrm{G}$ and $\mathrm{E}+\mathrm{G}$ groups. As we expected, the BAX/Bcl-2 ratio in the control and saline groups was significantly higher than that in the exercise $(\mathrm{p}<0.0001$ and $\mathrm{p}<0.0001)$, garlic $(p=0.0001$ and $p<0.0001)$ and E.G $(p<0.0001$ and $p<0.0001)$ groups. The E.G group depicted the lowest mean value of $\mathrm{BAX} / \mathrm{Bcl}-2$ ratio compared to the other groups; however, this difference was not significant when compared with $\mathrm{E}$ and $\mathrm{G}$ groups (Table 2).

\section{Urea, Uric Acid and Creatinine}

The mean of urea, uric acid and creatinine concentration in all groups is depicted in Table 3. A significant difference was observed for the mean of these factors between the groups $(p<0.001)$. The E.G group had the lowest mean value of renal damage biomarkers compared to other groups. The swimming exercise alone (E) or combined with garlic
(E.G) groups exhibited significantly lower mean value of urea, uric acid and creatinine than the control and saline groups $(\mathrm{p}<0.05)$. We did not find a significant difference in the mean levels of urea, uric acid and creatinine between the control, saline and garlic groups.

\section{Liver Enzymes}

The AST, ALT and ALP mean values are summarized in Table 4. There was a significant difference in the mean of three biomarkers between the groups $(p<0.001)$. The mean of AST in exercised alone or combined with garlic groups was significantly lower than that in the control $(\mathrm{p}=0.012$; $p=0.034)$ and saline $(p=0.007 ; p=0.03)$ groups. The E.G group also displayed a significant lower AST value as compared to the garlic group $(p=0.045)$. There was also a significant difference in the mean of ALT activity between all groups $(\mathrm{p}=0.001)$. The E.G and E groups demonstrated a significant lower mean ALT level than that in the control $(\mathrm{p}=0.026 ; \mathrm{p}=0.044)$ and saline $(\mathrm{p}=0.005 ; \mathrm{p}=0.008)$ groups. Considering the mean of ALP level, we found a significant difference between all groups $(\mathrm{p}<0.0001)$. The control and saline group showed the greater mean ALP value compared to $\mathrm{E} . \mathrm{G}(\mathrm{P}=0.005 ; \mathrm{P}=0.005), \mathrm{E}(\mathrm{P}=0.026 ; \mathrm{P}=0.023)$ and $\mathrm{G}(\mathrm{P}=0.011 ; \mathrm{P}=0.01)$ groups. There was no significant difference in ALT mean value between the other groups.

\section{Antioxidant and Lipid Peroxidation Biomarkers}

The means of CAT, SOD and MDA values in liver and kidney of all groups are presented in Table 5. The mean of CAT and SOD activities in liver and kidney was in the $\mathrm{E}+\mathrm{G}$ more than $\mathrm{G}, \mathrm{E}$, control and $\mathrm{S}$ groups, whereas the mean concentration of MDA was in the control more than $\mathrm{S}, \mathrm{E}$, $\mathrm{G}$ and $\mathrm{G}+\mathrm{E}$ groups. The mean of SOD activity in liver and kidney was significantly different between all groups $(\mathrm{p}<0.0001)$. Control and saline groups had significantly lower mean of liver SOD activity compared to the $\mathrm{E}(\mathrm{p}=0.002 ; \mathrm{p}=0.001), \mathrm{G}(\mathrm{p}<0.0001 ; \mathrm{p}<0.0001)$ and $\mathrm{E}+\mathrm{G}$ $(p<0.0001 ; p<0.0001)$ groups. The mean of renal SOD activity in the control and saline groups was also significantly lower than that in $E(p=0.007 ; p=0.006), G(p<0.003$; $\mathrm{p}=0.002)$ and $\mathrm{E}+\mathrm{G}(\mathrm{p}=0.001 ; \mathrm{p}<0.0001)$ groups.

The mean value of liver CAT activity was not significant between all groups $(\mathrm{p}=0.055)$, while, the mean of renal CAT activity was significantly different between all groups $(\mathrm{p}=0.001)$. Control and saline groups showed significantly lower mean CAT activity compared to the 


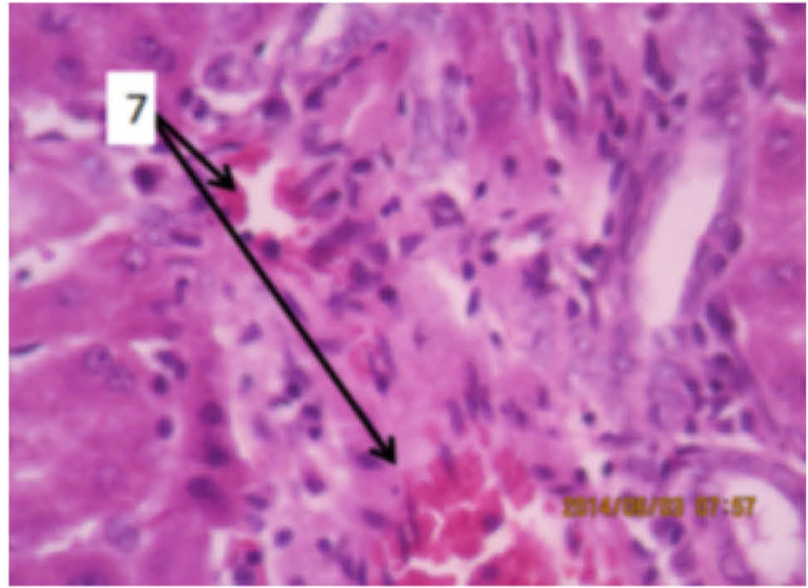

A

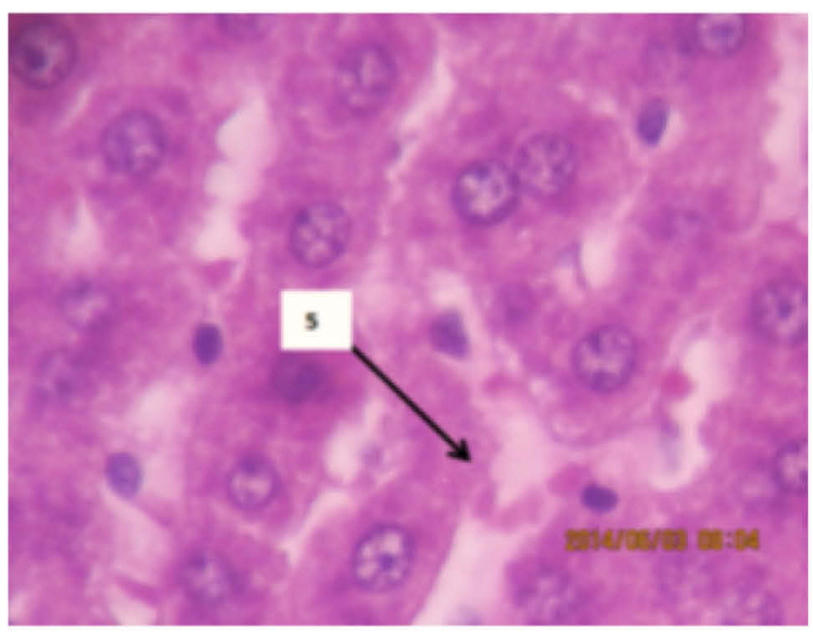

C

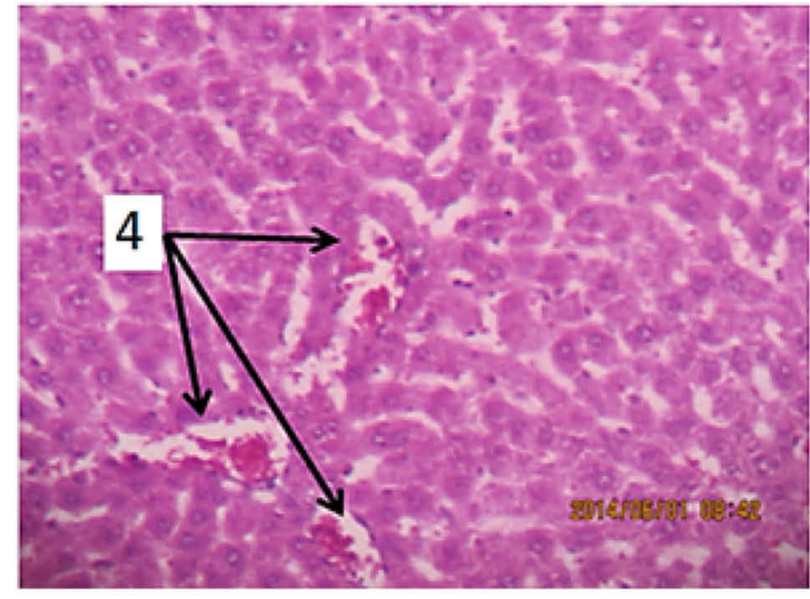

B

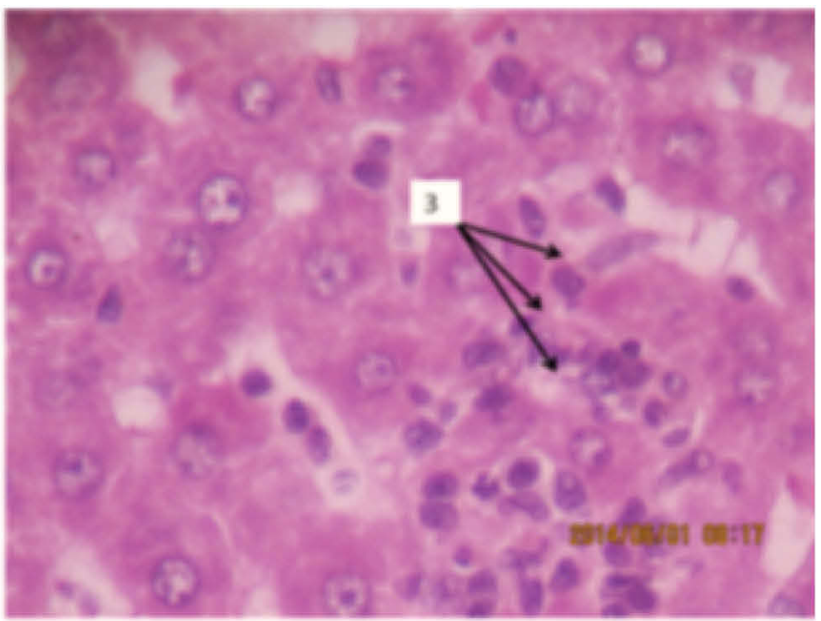

D

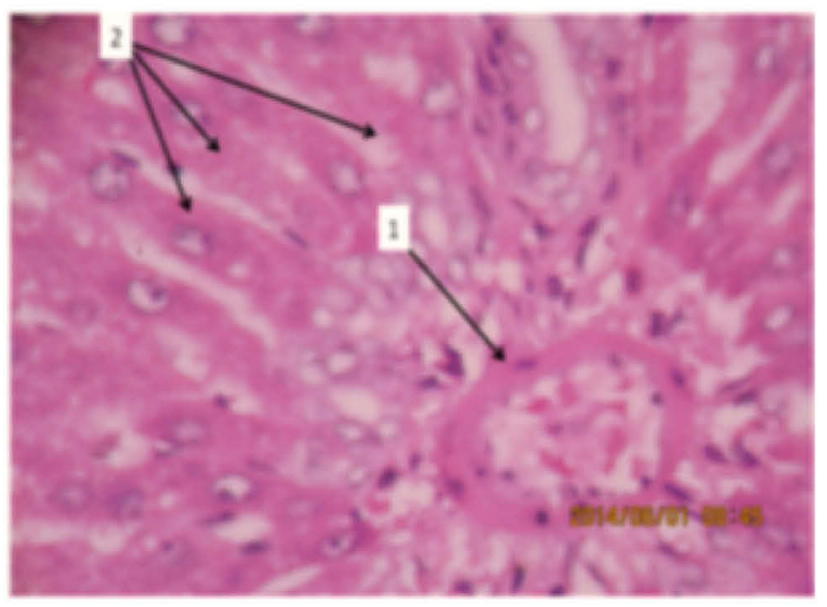

E

Figure I Sections of liver tissue from different groups. (A) Control, (B) saline, (C) garlic, (D) exercised, and (E) exercise + garlic groups: (I) central vein, (2) hepatocells; (3) and (7) mild parenchymal inflammation; (4) and (5) sinusoidal dilatation. 


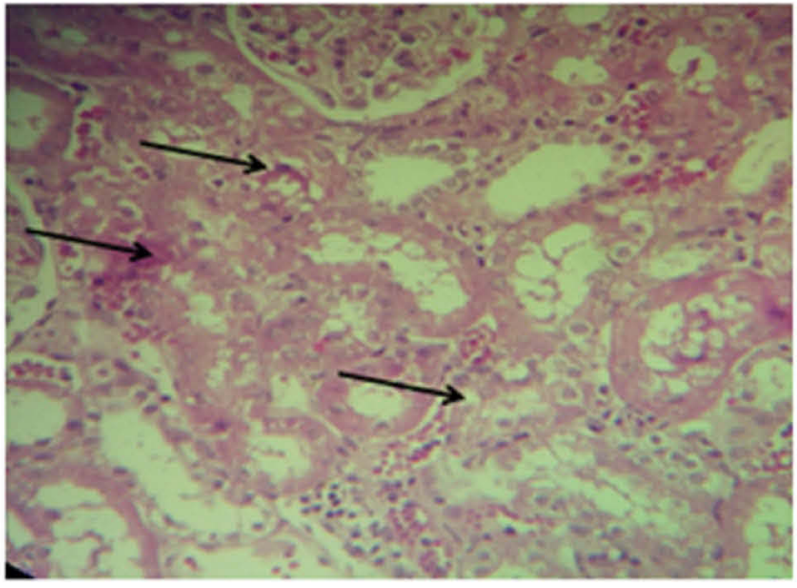

A

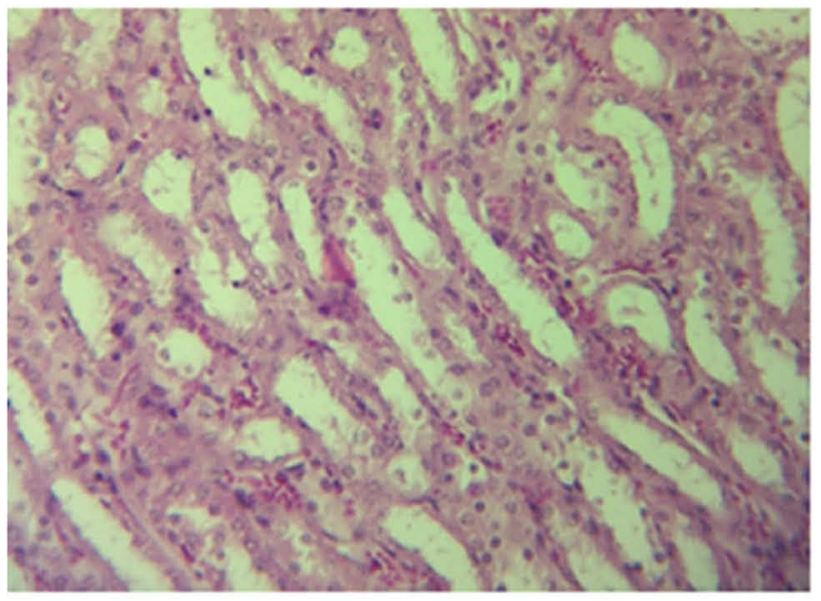

C

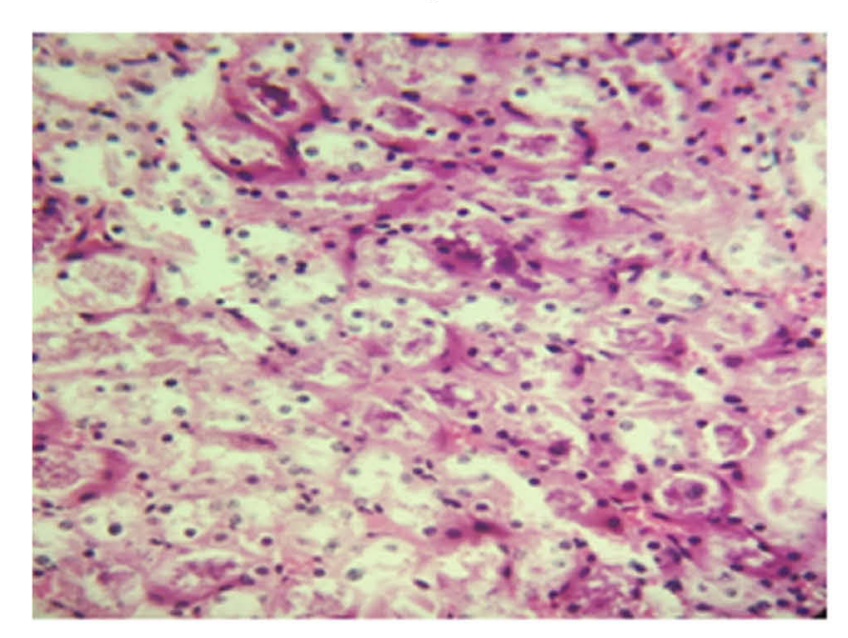

E

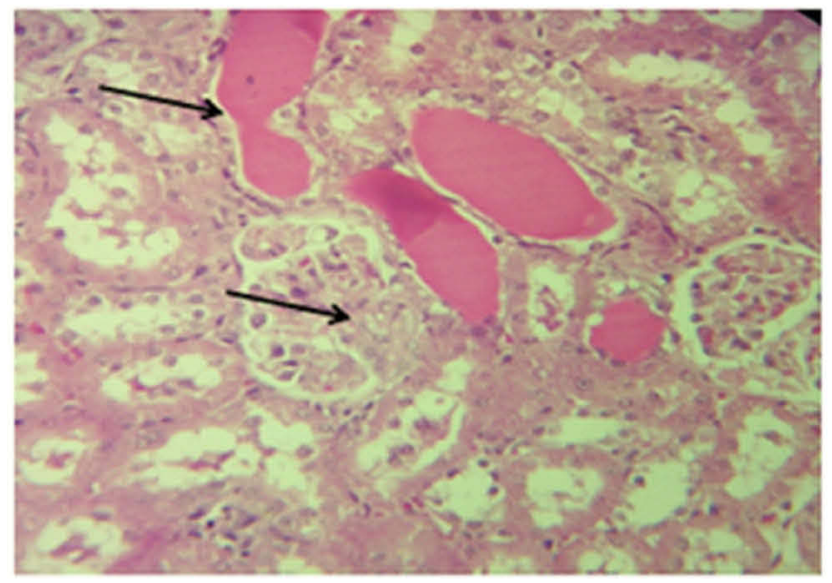

B

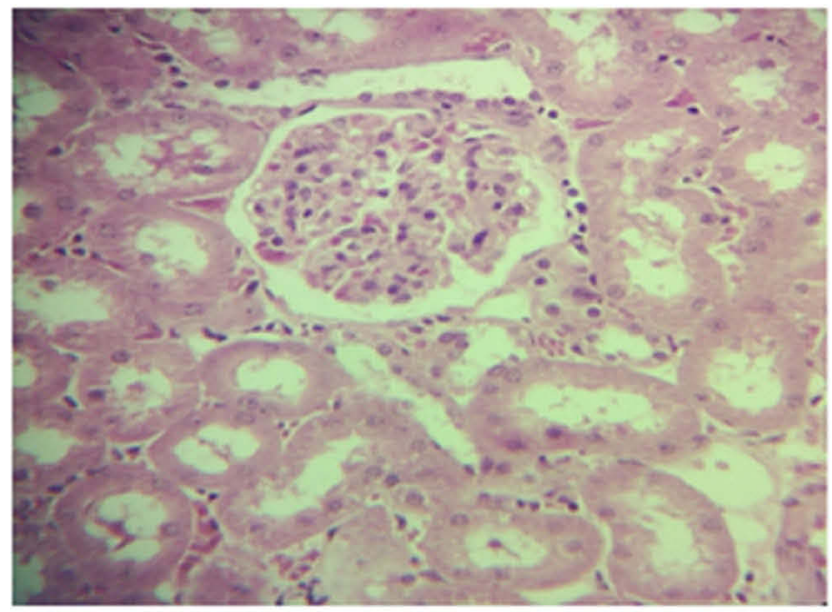

D

Figure 2 Sections of renal tissue from different groups: (A) control, (B) saline, (C) exercise, (D) garlic, and (E) exercise + garlic groups. Black arrows: mild necrosis, intratubular hemorrhage and sloughing of epithelium. 
Table 2 The Mean \pm SD of the Hepatic and Renal Apoptosis Biomarkers in Different Groups

\begin{tabular}{|c|c|c|c|c|c|c|}
\hline Parameters & Control & $\mathbf{S}$ & $\mathbf{E}$ & G & E.G & p-value \\
\hline \multicolumn{7}{|l|}{ Hepatic } \\
\hline BAX (ng/mg/tissue) & $9.16 \pm 1.4$ & $9.38 \pm 1.39$ & $6.98 \pm 1.77^{*}$ & $6.65 \pm 0.97^{*}$ & $6.37 \pm 0.92 *$ & $<0.001$ \\
\hline Bcl-2 (ng/mg/tissue) & $4.28 \pm 0.81$ & $4.12 \pm 0.95$ & $6.57 \pm 0.74 *$ & $7.08 \pm 0.9 *$ & $8.01 \pm 1.04 *$ & $<0.001$ \\
\hline $\mathrm{BAX} / \mathrm{Bcl}-2(\mathrm{ng} / \mathrm{mL})$ & $2.25 \pm 0.76$ & $2.33 \pm 0.44$ & $1.06 \pm 0.24 *$ & $0.96 \pm 0.23 *$ & $0.8 \mathrm{I} \pm 0.18^{*}$ & $<0.001$ \\
\hline \multicolumn{7}{|l|}{ Renal } \\
\hline BAX (ng/mg/tissue) & $13.9 \pm 1.07$ & $12.78 \pm 1.65$ & $11.26 \pm 2.18^{*}$ & $10.48 \pm 1.65 *$ & $10.16 \pm 1.43 *$ & $<0.001$ \\
\hline Bcl-2 (ng/mg/tissue) & $3.6 \mathrm{I} \pm 0.28$ & $3.19 \pm 0.66$ & $4.97 \pm 0.68 *$ & $4.75 \pm 0.7 I^{*}$ & $5.05 \pm 0.67^{*}$ & $<0.001$ \\
\hline $\mathrm{BAX} / \mathrm{Bcl}-2(\mathrm{ng} / \mathrm{mL})$ & $3.84 \pm 0.39$ & $4.5 \pm 1.12$ & $2.17 \pm 0.56^{*}$ & $2.39 \pm 0.54 *$ & $2.04 \pm 0.4 I^{*}$ & $<0.001$ \\
\hline
\end{tabular}

Note: ${ }^{*} \mathrm{p}<0.05$ is considered as significant compared to control and saline groups.

Abbreviations: S, saline; E, exercise trining; G, garlic; E.G, exercise training + garlic.

$\mathrm{E}(\mathrm{p}=0.047 ; \mathrm{p}=0.035), \mathrm{G}(\mathrm{p}=0.017 ; \mathrm{p}=0.012)$ and $\mathrm{E}+\mathrm{G}$ $(\mathrm{p}=0.012 ; \mathrm{p}<0.008)$ groups.

The average of MDA level in kidney and liver was found to be significantly different between all groups $(\mathrm{p}<0.0001)$. Control and saline groups showed significantly higher hepatic mean MDA level compared to the $\mathrm{E}(\mathrm{p}=0.003 ; \mathrm{p}=0.009), \mathrm{G}(\mathrm{p}=0.001 ; \mathrm{p}=0.003)$ and $\mathrm{E}+\mathrm{G}$ $(\mathrm{p}<0.0001 ; \mathrm{p}=0.001)$ groups. Additionally, the control and saline groups showed significantly higher renal mean MDA value as compared to the $E(p=0.011 ; p=0.016)$, $\mathrm{G}(\mathrm{p}<0.0001 ; \mathrm{p}=0.001)$ and $\mathrm{E}+\mathrm{G}(\mathrm{p}<0.0001 ; \mathrm{p}<0.0001)$ groups.

\section{Discussion}

In this research, we considered the effects of 8 weeks swimming exercise alone or combined with garlic extract on renal and hepatic function biomarkers and apoptosis biomarkers in male old rats. Our data have revealed that 8 weeks of training exercise, especially exercise supplemented with garlic extract, can reduce the degree of hepatic (AST, ALT and ALP) and renal damage (uric acid, urea, and creatinine) biomarkers in old rats. This improvement in the $\mathrm{E}+\mathrm{G}$ group was even more than that in exercise or garlic alone groups, suggesting a hepatoprotective and renal protective effect in old rats.

Several studies confirmed the positive effects of different exercises on kidney function. ${ }^{16-18}$ For example, in a study by Heck et al (2016), they evaluated the effects of combined therapy with swimming exercise (20 min session, 5 days/week during 4 weeks) and a diet supplemented with 1 ppm of $(\mathrm{PhSe}) 2$ on the hepatic metabolic alterations caused by aging in male Wistar rats. ${ }^{19}$ They found that the combined therapy with SW training can normalize the activities of AST and ALT. ${ }^{19}$ The protective role of exercise training on renal damage has been reported in pervious works. ${ }^{16,20,21}$

Table 3 The Mean \pm SD of Urea, Uric Acid and Creatinine Levels in Different Groups

\begin{tabular}{|l|l|l|l|l|l|l|}
\hline Parameters & Control & S & E & G & E.G & P-value \\
\hline Uric acid $(\mathrm{mg} / \mathrm{dl})$ & $0.67 \pm 0.09$ & $0.63 \pm 0.08$ & $0.49 \pm 0.06 *$ & $0.55 \pm 0.05^{*}$ & $0.47 \pm 0.09 *$ & $<0.0001$ \\
Urea $(\mathrm{mg} / \mathrm{dl})$ & $40.57 \pm 3.66$ & $41.28 \pm 5.15$ & $33.59 \pm 3.1^{*}$ & $36.08 \pm 3.92^{*}$ & $32.58 \pm 4.39 *$ & $<0.0001$ \\
Creatinine $(\mathrm{mg} / \mathrm{dl})$ & $0.5 \pm 0.05$ & $0.51 \pm 0.04$ & $0.43 \pm 0.03^{*}$ & $0.47 \pm 0.05^{*}$ & $0.42 \pm 0.07 *$ & $<0.0001$ \\
\hline
\end{tabular}

Note: ${ }^{*}<0.05$ is considered as significant compared to control and saline groups.

Abbreviations: S, saline; E, exercise training; G, garlic; E.G, exercise training+ garlic.

Table 4 The Mean \pm SD of Liver Enzyme Activity in Different Groups

\begin{tabular}{|l|l|l|l|l|l|l|}
\hline Parameters & Control & S & E & G & E.G & p-value \\
\hline AST (unit/l) & $154.66 \pm \mid 8.64$ & $156.37 \pm 18.87$ & $131.37 \pm \mid 6.83^{*}$ & $150.21 \pm \mid 3.12$ & $126.12 \pm \mid 3.99^{*}$ & 0.001 \\
ALT (unit/I) & $227.7 I \pm 25.25$ & $236 \pm 26.98$ & $191.62 \pm 25.23^{*}$ & $212.25 \pm \mid 7.96$ & $189 \pm 27.72^{*}$ & 0.001 \\
ALP (unit/I) & $408.44 \pm 22.43$ & $409.12 \pm 40.45$ & $359.5 \pm 25.27^{*}$ & $354.25 \pm 36.94^{*}$ & $349.75 \pm 26.17^{*}$ & $<0.0001$ \\
\hline
\end{tabular}

Note: ${ }^{*} p<0.05$ is considered as significant compared to control and saline groups.

Abbreviations: S, saline; E, exercise training; G, Garlic; E.G, exercise training + garlic. 
We also considered the effects of SW exercise training alone or supplemented with garlic on renal and hepatic cells apoptotic biomarkers. Interestingly, our data demonstrated that SW exercise, particularly combined with garlic supplementation, enhances the renal and hepatic Bcl-2 levels and reduces the mean value of BAX. Thus, swimming exercise supplemented with garlic significantly declined the ratio of Bax to Bcl-2 through the suppression of the Bax expression and enhancement of the Bcl-2 expression. Recent studies have indicated that cell death is inhibited by decreasing the ratio of the $\mathrm{Bax} 2$ to $\mathrm{Bcl}-2,{ }^{22}$ and the decreased $\mathrm{Bax} / \mathrm{Bcl}-2$ ratio inhibits cytochrome c release and caspase-3 activation and consequently decreases apoptosis. ${ }^{23}$ Much of the plant's biological activity is due to the presence of a sulfur compound called allicin, which has antioxidant, anticancer, and hepatic protection properties. ${ }^{24}$ The anti-apoptotic effects of allicin may be mediated through the regulation of mitogenactivated protein kinase $\mathrm{P}_{38}$, nuclear factor Kappa $\mathrm{B}$ and caspases 3 and $9 .{ }^{25}$ In a study by Jin et al (2014), they recommend swimming exercise for the prevention of apoptosis in multiple sclerosis (MS) patients. ${ }^{26}$ Leite et al (2016) reported that SW exercise with a (PhSe)2-supplementation enhances neuroprotection of old rats by reducing apoptosis and glial cell activation. ${ }^{27}$ The inhibitory effect of swimming exercise on apoptosis in the skeletal muscle of mice was also reported in a previous study. ${ }^{12}$ Similarly, Chen et al (2013) found that treadmill exercise upregulates Bcl-2 expression and downregulates the levels of Bax, superoxide dismutase (SOD), malondialdehyde (MDA), and cleaved Caspases 9, 3, 8, $12 .^{28}$ Fealy et al (2012) proposed that short-term exercise decreases a circulatory marker of hepatocyte apoptosis in obese patients with nonalcoholic fatty liver disease (NAFLD). ${ }^{11}$
Our data have also shown that SW exercise solely or combined with garlic supplementation not only decreases lipid peroxidation but also improves antioxidant enzyme activity in liver and kidney. These findings are in agreement with other research. Several lines of studies have demonstrated that swimming training exercise provides general oxidative balance in organs and tissues. ${ }^{29,30}$ For example, Martines et al (2011) demonstrated that moderate daily swimming training improves oxidative stress markers by decreasing lipid peroxidation (reduced MDA level) and enhancing antioxidant activity of SOD, CAT and glutathione peroxidase (GPx). ${ }^{31}$ In another study by Marcelino et al (2013), they found that maternal swimming exercise reduces reactive species levels in cerebellum, parietal cortex and hippocampus of female Wistar rats. ${ }^{32}$ Additionally, it improves the antioxidant status of CAT, GPXs, and SOD. ${ }^{32}$ In a study by Lima et al (2013), they revealed that swimming trained Wistar rats showed decreased MDA levels in liver mitochondria. ${ }^{33}$ One of the reasons in which exercise combined with garlic extract decline apoptosis as well as liver and kidney damage may be related to antioxidative properties of garlic extract as recent investigations have shown the existence of different antioxidative, anti-aging, anti-cancer, and antiinflammatory compounds in garlic extract. ${ }^{15,34}$ Garlic increases the cellular GPXs in liver, kidney, breast, testis and other cells. ${ }^{35}$ Garlic contains melatonin which is a powerful antioxidant. It was claimed that garlic improves SOD, GPX, and CAT activities. ${ }^{35}$ This effect could be contributed primarily to a variety of sulfur-containing compounds and their precursors. ${ }^{36}$ Furthermore, bioactive components of garlic may probably chelate the metal ions $(\mathrm{Cu}, \mathrm{Zn}, \mathrm{Mn})$ and result in scavenge the superoxide ions leading to cellular redox status balance. ${ }^{37}$

Table 5 The Mean \pm SD of Liver and Renal Antioxidant Activity in Different Groups

\begin{tabular}{|c|c|c|c|c|c|c|}
\hline Parameters & Control & $\mathbf{s}$ & ET & G & ET.G & p-value \\
\hline \multicolumn{7}{|l|}{ Liver } \\
\hline CAT (U/mg/protein) & $211.71 \pm 32.22$ & $209.28 \pm 14.89$ & $233.57 \pm 8.86$ & $235.0 \pm 10.61$ & $236.28 \pm 16.88$ & 0.055 \\
\hline SOD (U/mg/protein) & $63.14 \pm 11.33$ & $62.57 \pm 5.56$ & $79 \pm 5.38^{*}$ & $81.14 \pm 4.7^{*}$ & $82.28 \pm 5.52 *$ & $<0.0001$ \\
\hline MDA (U/mg/protein) & $17.85 \pm 5.39$ & $17.57 \pm 2.63$ & $12 \pm 2.94 *$ & $|0 \pm 1.4|^{*}$ & $9.42 \pm 0.97^{*}$ & $<0.0001$ \\
\hline \multicolumn{7}{|l|}{ Kidney } \\
\hline CAT (U/mg/protein) & $152.85 \pm 23.5$ & $152 \pm 6.97$ & $172.42 \pm 5.38 *$ & $|75.28 \pm 9.2|^{*}$ & $176.28 \pm 8.07^{*}$ & 0.001 \\
\hline SOD (U/mg/protein) & $41.28 \pm 10.9$ & $40.85 \pm 5.49$ & $55.71 \pm 5.52 *$ & $57.14 \pm 7.47^{*}$ & $59.28 \pm 5.73 *$ & $<0.0001$ \\
\hline MDA (U/mg/protein) & $34.57 \pm 9.14$ & $33.42 \pm 7.04$ & $21.85 \pm 4.48^{*}$ & $20.42 \pm 3.69 *$ & $19.14 \pm 3.43 *$ & $<0.0001$ \\
\hline
\end{tabular}

Note: ${ }^{*} p<0.05$ is considered as significant compared to control and saline groups.

Abbreviations: S, saline; E, exercise training; G, garlic; E.G, exercise training + garlic. 
In conclusion, the findings of the current study revealed that swimming exercise alone or in combination with garlic can reduce renal and hepatic apoptosis, oxidative damages, and improve antioxidant activities in the liver and kidney of old rats.

\section{Acknowledgment}

This work was supported by the Exercise Physiology, Faculty of Humanities, Islamic Azad University, Sari Branch, Iran. We would also like to appreciate the staffs of the exercise physiology centers of Islamic Azad University, Sari, Iran. This study was supported by a grant received from Islamic Azad University, Sari Branch, Iran. All authors contributed to data analysis, drafting or revising the article, gave final approval of the version to be published, and agree to be accountable for all aspects of the work.

\section{Disclosure}

The authors report no conflicts of interest in this work.

\section{References}

1. Elmore S. Apoptosis: a review of programmed cell death. Toxicol Pathol. 2007;35(4):495-516. doi:10.1080/01926230701320337

2. Zeiss CJ. The apoptosis-necrosis continuum: insights from genetically altered mice. Vet Pathol. 2003;40(5):481-495. doi:10.1354/ vp. $40-5-481$

3. Vucicevic K, Jakovljevic V, Colovic N, et al. Association of Bax expression and $\mathrm{Bcl} 2 / \mathrm{Bax}$ ratio with clinical and molecular prognostic markers in chronic lymphocytic leukemia. J Med Biochem. 2016;35 (2):150-157. doi:10.1515/jomb-2015-0017

4. Chicco AJ, Hydock DS, Schneider CM, Hayward R. Low-intensity exercise training during doxorubicin treatment protects against cardiotoxicity. J Appl Physiol. 2006;100(2):519-527. doi:10.1152/ japplphysiol.00148.2005

5. Park SY, Kwak YS. Impact of aerobic and anaerobic exercise training on oxidative stress and antioxidant defense in athletes. $J$ Exercise Rehabil. 2016;12(2):113-117. doi:10.12965/jer.1632598.299

6. Lanzotti V. The analysis of onion and garlic. J Chromatogr A. 2006;1112(1-2):3-22. doi:10.1016/j.chroma.2005.12.016

7. Zare A, Farzaneh P, Pourpak Z, et al. Purified aged garlic extract modulates allergic airway inflammation in $\mathrm{BALB} / \mathrm{c}$ mice. Iran J Allergy Asthma Immunol. 2008;7(3):133-141.

8. Kruger K, Mooren FC. Exercise-induced leukocyte apoptosis. Exerc Immunol Rev. 2014;20:117-134

9. Phaneuf S, Leeuwenburgh C. Apoptosis and exercise. Med Sci Sports Exerc. 2001;33(3):393-396. doi:10.1097/00005768-200103000-00010

10. Podhorska-Okolow M, Dziegiel P, Gomulkiewicz A, et al. Exerciseinduced apoptosis in rat kidney is mediated by both angiotensin II AT1 and AT2 receptors. Histol Histopathol. 2006;21(5):459-466. doi:10.14670/HH-21.459

11. Fealy CE, Haus JM, Solomon TP, et al. Short-term exercise reduces markers of hepatocyte apoptosis in nonalcoholic fatty liver disease. $J$ Appl Physiol. 2012;113(1):1-6. doi:10.1152/japplphysiol.00 127.2012

12. Sun Y, Cui D, Zhang Z, et al. Attenuated oxidative stress following acute exhaustive swimming exercise was accompanied with modified gene expression profiles of apoptosis in the skeletal muscle of mice. Oxid Med Cell Longev. 2016;2016:8381242. doi:10.1155/2016/8381242
13. Ghyasi R, Mohaddes G, Naderi R. Combination effect of voluntary exercise and garlic (Allium sativum) on oxidative stress, cholesterol level and histopathology of heart tissue in type 1 diabetic rats. J Cardiovasc Thorac Res. 2019;11(1):61-67. doi:10.15171/jcvtr.2019.10

14. Peng CC, Chen KC, Hsieh CL, Peng RY. Swimming exercise prevents fibrogenesis in chronic kidney disease by inhibiting the myofibroblast transdifferentiation. PLoS One. 2012;7(6):e37388. doi:10.1371/journal.pone. 0037388

15. Seo DY, Kwak HB, Lee SR, et al. Effects of aged garlic extract and endurance exercise on skeletal muscle FNDC-5 and circulating irisin in high-fat-diet rat models. Nutr Res Pract. 2014;8(2):177-182. doi:10.4162/nrp.2014.8.2.177

16. Cao G, Gonzalez J, Muller A, et al. Beneficial effect of moderate exercise in kidney of rat after chronic consumption of cola drinks. PLoS One. 2016;11(3):e0152461. doi:10.1371/journal.pone.0152461

17. Pinheiro-Mulder A, Aguila MB, Bregman R, Mandarim-de-Lacerda CA. Exercise counters diet-induced obesity, proteinuria, and structural kidney alterations in rat. Pathol Res Pract. 2010;206 (3):168-173. doi:10.1016/j.prp.2009.11.004

18. Darnley MJ, DiMarco NM, Aukema HM. Safety of chronic exercise in a rat model of kidney disease. Med Sci Sports Exerc. 2000;32 (3):576-580. doi:10.1097/00005768-200003000-00005

19. Heck SO, Fulco BC, Quines CB, et al. Combined therapy with swimming exercise and a diet supplemented with diphenyl diselenide is effective against age-related changes in the hepatic metabolism of rats. J Cell Biochem. 2016;118:1574.

20. Chen WC, Huang WC, Chiu CC, Chang YK, Huang CC. Whey protein improves exercise performance and biochemical profiles in trained mice. Med Sci Sports Exerc. 2014;46(8):1517-1524. doi:10.1249/MSS.0000000000000272

21. Luiz Rda S, Silva KA, Rampaso RR, et al. Exercise attenuates renal dysfunction with preservation of myocardial function in chronic kidney disease. PLoS One. 2013;8(2):e55363. doi:10.1371/journal.pone.0055363

22. Almeida OF, Conde GL, Crochemore C, et al. Subtle shifts in the ratio between pro- and antiapoptotic molecules after activation of corticosteroid receptors decide neuronal fate. FASEB j. 2000;14 (5):779-790. doi:10.1096/fasebj.14.5.779

23. Pollack M, Phaneuf S, Dirks A, Leeuwenburgh C. The role of apoptosis in the normal aging brain, skeletal muscle, and heart. Ann N Y Acad Sci. 2002;959(1):93-107. doi:10.1111/j.1749-6632.2002.tb02086.x

24. Ide N, Lau BH. Garlic compounds minimize intracellular oxidative stress and inhibit nuclear factor- $\mathrm{kB}$ activation. $J$ Nutrition. 2001;131 (3):1020S-6S. doi:10.1093/jn/131.3.1020S

25. Cheng SM, Cheng YJ, Wu LY, Kuo CH, Lee YS, Wu MC. Activated apoptotic and anti-survival effects on rat hearts with fructose induced metabolic syndrome. Cell Biochem Funct. 2014;32(2):133-141. doi: $10.1002 / \mathrm{cbf} .2982$

26. Jin JJ, Ko IG, Kim SE, Shin MS, Kim SH, Jee YS. Swimming exercise ameliorates multiple sclerosis-induced impairment of short-term memory by suppressing apoptosis in the hippocampus of rats. J Exercise Rehabil. 2014;10(2):69-74. doi:10.12965/jer.140103

27. Leite MR, Cechella JL, Pinton S, Nogueira CW, Zeni G. A diphenyl diselenide-supplemented diet and swimming exercise promote neuroprotection, reduced cell apoptosis and glial cell activation in the hypothalamus of old rats. Exp Gerontol. 2016;82:1-7. doi:10.1016/j.exger.2016.05.006

28. Chen KC, Peng CC, Hsieh CL, Peng RY. Exercise ameliorates renal cell apoptosis in chronic kidney disease by intervening in the intrinsic and the extrinsic apoptotic pathways in a rat model. Evidence-Based Complementary Altern Med. 2013;2013:368450.

29. Elikov AV. Oxidative balance in rats during adaptation to swimming load. Bull Exp Biol Med. 2016;162(2):180-183. doi:10.1007/s10517016-3570-4

30. Claudio ER, Endlich PW, Santos RL, et al. Effects of chronic swimming training and oestrogen therapy on coronary vascular reactivity and expression of antioxidant enzymes in ovariectomized rats. PLoS One. 2014;8(6):e64806. doi:10.1371/journal.pone.0064806 
31. Martins RR, de Oliveira Macedo UB, Leite LD, Rezende AA, Brandao-Neto J, Almeida M. Lipoic acid and moderate swimming improves the estrous cycle and oxidative stress in Wistar rats. Appl Physiol Nutrition Metab. 2011;36(5):693-697. doi:10.1139/h11-074

32. Marcelino TB, Longoni A, Kudo KY, et al. Evidences that maternal swimming exercise improves antioxidant defenses and induces mitochondrial biogenesis in the brain of young Wistar rats. Neuroscience. 2013;246:28-39. doi:10.1016/j.neuroscience.2013.04.043

33. Lima FD, Stamm DN, Della-Pace ID, et al. Swimming training induces liver mitochondrial adaptations to oxidative stress in rats submitted to repeated exhaustive swimming bouts. PLoS One. 2013;8(2):e55668. doi:10.1371/journal.pone.0055668
34. Pinto JT, Rivlin RS. Antiproliferative effects of allium derivatives from garlic. J Nutr. 2001;131(3s):1058S-60S. doi:10.1093/jn/131.3.1058S

35. Pal R, Vaiphei K, Arbab S, Kartar S. The effect of garlic on isoniazid and rifampicin-induced hepatic injury in rats. World J Gastroenterol. 2006;28(12):636-639. doi:10.3748/wjg.v12.i4.636

36. Nishimura $H$, Higuchi $O$, Tateshita $K$. Antioxidative activity of sulfur-containing compounds in Allium species for human LDL oxidation in vitro. Biofactors. 2004;21(1-4):277-280. doi:10.1002/biof.552210154

37. Rajani Kanth V, Uma Maheswara Reddy P, Raju TN. Attenuation of streptozotocin-induced oxidative stress in hepatic and intestinal tissues of Wistar rat by methanolic-garlic extract. Acta Diabetol. 2008;45(4):243-251. doi:10.1007/s00592-008-0051-X

\section{Publish your work in this journal}

Clinical Interventions in Aging is an international, peer-reviewed journal focusing on evidence-based reports on the value or lack thereof of treatments intended to prevent or delay the onset of maladaptive correlates of aging in human beings. This journal is indexed on PubMed Central, MedLine, CAS, Scopus and the Elsevier
Bibliographic databases. The manuscript management system is completely online and includes a very quick and fair peer-review system, which is all easy to use. Visit http://www.dovepress.com/ testimonials.php to read real quotes from published authors. 